\section{Canções escravas, trânsitos musicais atlânticos e racismo nas Américas.}

Sílvia Cristina Martins Souza [*]

[*] Universidade Estadual de Londrina Londrina (PR) - Brasil.

E-mail:smartins@uel.br

ORCID: https://orcid.org/0000-0002-8824-4477

ABREU, Martha. Da senzala ao palco: canções escravas e racismo nas Américas (1870-1930). Campinas: Editora Unicamp, 2017, 462 p. (Coleção Históri@ Ilustrada).
Resumo: $\mathrm{O}$ artigo destina-se a resenhar o livro $\mathrm{Da}$ senzala ao palco: canções escravas e racismo nas Américas, de autoria de Martha Abreu.

Palavras-chave: Escravidão; Cultura negra; Música.

Canções escravas, atlantic musical traffic and racism in the Americas

Abstract: This article aims to review the book Da senzala ao palco: canções escravas e racism nas Américas by Martha Abreu.

Keywords: Slavery; Black culture; Music. 

s estudos sobre escravidão no Brasil passaram por transformações significativas a partir dos anos 1980, fruto do diálogo travado com uma historiografia internacional renovada, mas também impulsionados pelo fortalecimento dos movimentos negros; pelas ações públicas de combate ao racismo; pela compreensão sobre as lutas políticas, sociais e raciais; e pela disseminação das noções de diversidade cultural e racial. Essa historiografia desde então tem investido no enfrentamento de alguns desafios, entre uma série de outros: o de mostrar que os debates sobre as expressões culturais não podem prescindir de entender os embates sobre a questão racial nelas contidos, bem como a necessidade de denunciar as falácias contidas em mitos, visões e modelos interpretativos que por muito tempo deram o tom dos trabalhos nesta área.

Se os anos 1980 são referenciais para os estudos sobre escravidão, os anos 2000 marcam a emergência dos estudos sobre o pós-abolição e a constituição de um campo historiográfico que apresenta peculiaridades, apesar de sua íntima e reconhecida relação com a história social da escravidão e do processo de abolição.

Os diálogos travados entre a historiografia norte-americana e a brasileira sobre a escravidão e o pós-abolição não são recentes, mas tomaram rumos diferentes nas últimas décadas, em decorrência de algumas constatações. Entre elas destaca-se o reconhecimento de que, a despeito das especificidades dos sistemas escravistas e dos processos de abolição nos Estados Unidos e no Brasil, existem conflitos e experiências dos escravizados e libertos nas Américas que podem ser aproximados, desde que utilizadas metodologias e fontes adequadas, o que significa admitir a impossibilidade de pensar a diáspora africana a partir de histórias isoladas ou desconectadas.

Tal percepção tem ensejado um retorno às abordagens comparativas que já haviam alimentado alguns debates sobre instituições, culturas e organizações sociais nos anos 1940 e 1970, mas foram negligenciadas com a rejeição dos estudos dessa natureza pela historiografia norte-americana e, na historiografia latino-americana, pela concentração em estudos locais (Klein, 2012, p. 95).

A busca por novos procedimentos de análise para pensar problemas, definição de objetos de pesquisa e modos narrativos tem levado os historiadores a questionar a eficiência da própria História Comparada no seu projeto de superação dos limites da perspectiva nacionalista. A necessidade de considerar a nação mais um (e não o mais importante) fenômeno a ser elucidado, e as comparações entre nações mais como temas do que como métodos, tornou-se um objetivo perseguido em trabalhos desenvolvidos em diferentes perspectivas, tais como as Histórias Atlânticas, as Histórias Globais, as Histórias Conectadas, as Histórias Cruzadas e as Histórias Transnacionais (Barros, 2014, p. 280).

Analisar as identidades negras culturalmente híbridas e dinâmicas da diáspora, construídas a partir da memória do trauma original da escravidão e dos desdobramentos do pós-abolição com suas vivências de violência racial e racismo, é o objeto do trabalho referencial 
de Paul Gilroy intitulado O Atlântico Negro: modernidade e dupla consciência (2001). No prefácio à edição brasileira dessa obra, Gilroy sugere que o conceito de Atlântico Negro muito teria a ganhar se a ele fossem incorporados o Atlântico Sul e suas múltiplas configurações culturais (Gilroy, 2001, p. 16).

Da senzala ao palco: canções escravas e racismo nas Américas (1870-1930), o mais recente livro de Martha Abreu, é uma resposta muito bem-sucedida a esse desafio. Trata-se de um trabalho que abre novas possibilidades para os estudos das culturas e identidades negras no Brasil, em diálogo com os Estados Unidos, e insere o nome de sua autora de maneira definitiva numa historiografia de perspectiva atlântica ao lado de nomes como Micol Seigel, Denis-Constant Martin, Robin Moore, Sarah Merr, David Guss, Astrid Kusser e Kazadi wa Mukuna, entre outros.

O livro de Martha Abreu é um dos frutos dos caminhos trilhados por uma historiadora que elegeu as manifestações culturais populares como seu local de sondagem do mundo. Suas escolhas a conduziram por uma trajetória que, em suas próprias palavras, a transformou de "uma historiadora da festa e da cultura popular em uma historiadora do legado da canção escrava, do racismo no campo musical e cultural e dos caminhos construídos pelos músicos e artistas negros para enfrentá-lo e subvertê-lo". Nesse percurso, Da senzala ao palco emerge como um ponto alto na produção de uma intelectual que tem contribuído com perspectivas inovadoras aos debates sobre a dinâmica das culturas e identidades negras atlânticas tanto na academia, como professora e pesquisadora, quanto na História Pública, nos projetos e ações relacionados a comunidades quilombolas e jongueiras e na transformação de suas memórias do cativeiro e da liberdade em luta contra o racismo, pelo direito à terra, pela igualdade e pela justiça.

O livro é o terceiro volume da Coleção Históri@ Ilustrada, publicada pela Editora Unicamp, fruto do trabalho de pesquisadores vinculados ao Centro de Pesquisa em História Social da Cultura (IFCH/Unicamp), do qual Martha Abreu participa desde a criação. O texto encontra-se disponível em dois formatos digitais: ePUB3 (com links internos para acesso a imagens, áudio e vídeo) e ePUB2 (com links internos para acesso a imagens e externos para áudio e vídeo). Com isso, Da senzala ao palco não apenas atinge um público amplo como também seus leitores têm a oportunidade de acessar 200 imagens, quase 50 fonogramas e 5 vídeos. Paralelamente ao livro, foi produzido um vídeo de 10 minutos intitulado Canções escravas e racismo nas Américas, que com ele dialoga, ajuda a divulgá-lo e pode ser utilizado por professores nas escolas e no ensino de História. ${ }^{1}$

Utilizando-se de um rico corpus documental e de uma vasta bibliografia especializada, a autora enfrenta basicamente quatro grandes questões ao longo de seu texto: os trânsitos

${ }^{1} \mathrm{O}$ vídeo pode ser acessado em: <https://www.youtube.com/watch?v=agZPb-uEVto> 
internacionais, as canções escravas no mundo do entretenimento, as ações dos músicos negros e as construções do racismo no campo musical.

O objetivo central do livro é elaborar uma análise que aproxime as experiências de músicos negros e diferentes produtores e divulgadores das canções escravas nos Estados Unidos e no Brasil, no período que abrange de 1870 a 1930, a partir de problemas e fontes comuns e equivalentes. Sua intenção é, contudo, menos a de reforçar as evidentes diferenças entre os dois países, e mais destacar diálogos e aproximações nas formulações e experiências dos músicos negros e sobre música negra nas Américas. Trata-se, como se pode perceber, de uma história das expressões musicais da cultura negra escrita numa perspectiva atlântica que amplia os estudos sobre o pós-abolição ao sul do equador.

Cultura negra é um conceito central para a obra, embora não seja pensado ou utilizado pela autora como fechado e definitivo, mas enfrentado no seu próprio fazer historiográfico, através do uso das fontes e da metodologia. Ele remete às expressões culturais protagonizadas por afrodescendentes nas Américas e contém em seu âmago as noções de diáspora e desterritorialização por meio de estruturas transnacionais criadas e desenvolvidas na modernidade e marcadas por um sistema de comunicações permeado por fluxos e trocas culturais. Cultura negra é, portanto, um conceito que possibilita colocar em campo diferentes sujeitos sociais e diversas expressões e representações artísticas numa arena de conflitos. Ele indica, também, a intenção de questionar os estudos culturais marcados por perspectivas etnocêntricas e uma oposição à noção de que a cultura sempre flui em padrões que correspondem às fronteiras do Estado-nação.

Canções escravas ou "sons do cativeiro", termos tomados de empréstimo a Shane e Graham White (White e White, 2005, p. ?), são expressões que não devem levar à falsa impressão de que a obra se dedica à escuta da sonoridade ou das formas musicais e estilísticas africanas presentes nas Américas, como esclarece Martha Abreu já nas páginas iniciais do livro. Entendidos como resultado da combinação de música, verso e dança, Canções escravas ou "sons do cativeiro" são termos alternadamente utilizados no livro para nomear as invenções musicais dos descendentes de africanos trazidos como escravos para o continente americano, as quais ganharam visibilidade e aceitação por meio da ação de músicos negros e de uma complexa rede de agentes que alimentou um cobiçado mercado musical que movimentava negócios de impressão e venda de partituras, espetáculos teatrais e indústria fonográfica. Vistas a partir desse ângulo, as canções escravas são decorrência de trânsitos e interações, tanto nacionais quanto transnacionais, e abrangem diferentes atores sociais, ainda que protagonizadas por músicos e atores negros.

Entre as principais fontes utilizadas por Martha Abreu, destacam-se textos de intelectuais que se preocuparam em entender e avaliar as "influências" dos africanos nas músicas e danças populares e nacionais, gravações fonográficas e, sobretudo, partituras musicais comercializadas em lojas de vendas de partituras, pianos, fonógrafos e discos, impressas 
pelas muitas editoras musicais existentes na ocasião. É digna de nota, nesse sentido, a análise minuciosa e instigante da autora sobre um extenso e significativo conjunto de capas de partituras cujas temáticas, títulos, gêneros, formas musicais e/ou ilustrações apresentam referências que remetem ao passado e às memórias do cativeiro, bem como a estereótipos e cenas racistas identificados com a população afro-americana no pós-abolição.

O livro organiza-se em nove capítulos abundantemente documentados - alguns deles anteriormente publicados em revistas especializadas (os de número 7, 8 e 9), mas modificados para essa publicação - , nos quais a autora aborda uma ampla pauta de questões. Entre elas encontram-se as experiências de músicos negros e destes com diferentes sujeitos envolvidos na produção e divulgação das canções escravas que alimentaram os trânsitos atlânticos no sentido Norte-Sul e vice-versa; as apropriações de gêneros, ritmos e formas musicais relacionados com africanos por músicos de formação erudita; as dimensões políticas das expressões musicais ligadas ao passado escravista; as experiências sociais e vivências de diferentes formas de racismo que aproximam as culturas negras e seus agentes; os significados das canções escravas para diferentes sujeitos negros, como os artistas Eduardo das Neves e Bert Williams e intelectuais acadêmicos como Coelho Netto e Du Bois; as aproximações entre as figuras de personagens como Pai João, Uncle Tom, Uncle Remus e Sambo, presentes na indústria fonográfica e na literatura popular, bem como as conexões transnacionais de gêneros musicais identificados e protagonizados por músicos negros, como o maxixe, que foi rapidamente assimilado nos Estados Unidos em função das suas proximidades com o cakewalk.

A leitura não é operação desprovida de sentido, pois quem lê busca significados, recorre a significantes, ritmos e formas e, nesse movimento, influenciam-se os modos de sentir, pensar e agir. Ao terminar a leitura do livro de Martha Abreu, o leitor provavelmente terá a sensação de ver abaladas determinadas certezas a respeito de algumas interpretações tradicionais sobre nosso passado musical ao constatar que elas não dão conta de um quadro muito mais rico e complexo.

São consideráveis, por exemplo, as contribuições do livro para se repensar determinadas versões sobre a história da música no Brasil, construídas com base nos marcos nacionalistas dos anos 1920 e 1930 ou na política cultural dos governos Vargas. E isso porque as discussões sobre as canções escravas nele presentes evidenciam quanto as manifestações musicais ditas nacionais só se sustentam e legitimam em contatos transnacionais por meio dos quais dialogam em termos referenciais, de elementos humanos e obtêm reconhecimento cultural. Nesse sentido, pode-se dizer que o livro de Martha Abreu nos mostra o tanto de transnacional que contém a noção de música nacional.

O leitor também perceberá quanto o campo musical foi um espaço minado, poroso e permeado por tensões e conflitos nos quais se travaram disputas em torno das representações dos descendentes de africanos e de seu patrimônio cultural e de como eles foram sujeitos ativos nesse processo. Coube a eles ampliar e redefinir discussões acerca das culturas 
nacionais, dos gêneros musicais, do legado da escravidão e das experiências do racismo que se reconstruíam em diferentes campos da indústria cultural no pós-abolição.

Por fim, mas não em último lugar, o livro oferece argumentos bastante consistentes para questionar visões que tradicionalmente polarizaram as relações raciais no Brasil e nos Estados Unidos entre mestiçagem, de um lado, e segregacionismo, de outro. Martha nos mostra como existem variantes, mediações e matizes que não podem ser desconsiderados em análises que objetivem romper com interpretações dicotômicas e generalizantes, que pouco contribuem para melhor conhecer um fenômeno bastante complexo, tanto para o Atlântico Norte, quanto para o Sul.

\section{Referências bibliográficas}

BARROS, José D’Assunção. Histórias cruzadas: considerações sobre uma nova modalidade baseada nos procedimentos relacionais. Anos 90 (Porto Alegre), v. 21, n. 40, dez. 2014.

GILROY, Paul. O Atlântico Negro: modernidade e dupla consciência. Rio de Janeiro: Editora 34, 2001.

KLEIN, Herbert S. A experiência afro-americana numa perspectiva comparativa: situação atual do debate sobre a escravidão nas Américas. Revista Afro-Ásia (Salvador), n. 45, 2012.

WHITE, Shane; WHITE, Graham. The sound of slavery: discovering African American history through songs, sermons and speech. Boston: Beacon Press, 2005. 